\title{
Determination of metabolites of phloretin in rats using UHPLC-LTQ-Orbitrap mass spectrometry
}

\author{
Fang Ping Wu, Liang Hong Liu, Ping Jin, Hong Pu, Zu Fu Yao, Wei Cai* \\ Hunan Provincial Key Laboratory of Dong Medicine, Hunan University of Medicine, Huaihua, China; School of Pharmaceutical \\ Sciences, Hunan University of Medicine, Huaihua, Hunan 418000, China
}

*For correspondence: Email: caiyunrui357743447@163.com

Sent for review: 15 May 2019

Revised accepted: 22 September 2019

\begin{abstract}
Purpose: To study the metabolites of phloretin in vivo using ultra-high performance liquid chromatography linear ion trap-Orbitrap mass spectrometry (UHPLC-LTQ-Orbitrap).

Methods: After administration of phloretin (50 mg/kg; oral route) to six rats, blood samples were taken from each animal. Each sample was then subjected to solid-phase extraction to prepare it for chromatographic/spectroscopic analysis. Finally, each sample was analyzed using UHPLC-LTQOrbitrap with a negative-mode electrospray ionization source.

Results: Based on mass measurements, chromatographic retention times, and MS2 fragmentation ions, we detected and identified phloretin and 16 metabolites of the drug in vivo in rats. Metabolic reactions of phloretin included glucosylation and glucuronide conjugation, diglucuronide conjugation, glucosylation and sulfate conjugation, sulfate conjugation, glucuronide conjugation, and glucosylation and hydroxylation.

Conclusion: The findings provide a better understanding of phloretin metabolism and metabolites, and new information about their effective forms, pharmacological actions, metabolic fate, and toxic actions in vivo.
\end{abstract}

Keywords: Phloretin, Ultra-performance liquid chromatography LTQ-Orbitrap mass spectrometry (UHPLC-LTQ-Orbitrap MS), Metabolites

\begin{abstract}
This is an Open Access article that uses a fund-ing model which does not charge readers or their institutions for access and distributed under the terms of the Creative Commons Attribution License (http://creativecommons.org/licenses/by/4.0) and the Budapest Open Access Initiative (http://www.budapestopenaccessinitiative.org/read), which permit unrestricted use, distribution, and reproduction in any medium, provided the original work is properly credited.

Tropical Journal of Pharmaceutical Research is indexed by Science Citation Index (SciSearch), Scopus, International Pharmaceutical Abstract, Chemical Abstracts, Embase, Index Copernicus, EBSCO, African Index Medicus, JournalSeek, Journal Citation Reports/Science Edition, Directory of Open Access Journals (DOAJ), African Journal Online, Bioline International, Open-J-Gate and Pharmacy Abstracts
\end{abstract}

\section{INTRODUCTION}

The chemical name of phloretin is $3-(4-$ Hydroxyphenyl)-1-(2,4,6-trihydroxyphenyl)-1propanone (i.e., dihydrochalcone). It can be isolated from Lithocarpus litseifolius (Hance) Chun (sweat tea) leaves and used as a tea and folk medicine to treat various disorders (e.g., diabetes, hypertension, and epilepsy). Pharmacological studies have found that phloretin has anti-oxidant [1], anti-tumor [2-4], anti-apoptosis [5], anti-inflammatory, immunosuppressive [6], and cardiovascularprotective effects [7-10]. The metabolism of phloretin should be examined in vivo to clarify its mechanisms of action and increase its availability for disease treatment.

Drug metabolites are typically characterized structurally in vivo and in vitro by liquid 
chromatography/mass spectrometry methods $[11,12]$. Due to the shorter times required and higher-yield separation and accurate resolution capacities, ultra-high-performance liquid chromatography (UHPLC) coupled with highresolution mass spectrometry (e.g., the UHPLClinear ion trap (LTQ)-Orbitrap) significantly contributes to the accurate and efficient characterization of drug metabolites $[13,14]$.

\section{EXPERIMENTAL}

\section{Chemicals and reagents}

Grace Pure ${ }^{\mathrm{TM}}$ SPE $\mathrm{C} 18$ phase extraction cartridges $(200 \mathrm{mg} / 3 \mathrm{~mL}, 59 \mu \mathrm{m}, 70 \AA$ ) were obtained from Grace Davison Discovery Science $^{\mathrm{TM}}$ (Deerfield, IL, USA). HPLC-grade acetonitrile was obtained from Fisher (Fair Lawn, NJ, USA). Ultra-pure water was generated using a Milli-Q water purification system from Millipore (Billerica, MA, USA). All other reagents used in this study were analytical grade and commercially available.

The phloretin was purchased from Nanjing Spring and Autumn Biological Engineerin gCo. Ltd. Its structure was determined from UV, MS, ${ }^{1} \mathrm{H}-\mathrm{NMR}$, and ${ }^{13} \mathrm{C}-\mathrm{NMR}$ results and from a comparison of those results with previously published data. HPLC analysis revealed that the phloretin purity was $>98 \%$. The structure is shown in Figure 1.<smiles>O=C(CCc1ccc(O)cc1)c1c(O)cc(O)cc1O</smiles>

Figure 1: Structure of phloretin

\section{Animals and drug administration}

Sprague-Dawley rats (six male rats; body weight range, $200-250 \mathrm{~g}$; Beijing Wei tong Li hua Experimental Animals Company, Beijing, China) were kept in controlled environmental conditions (relative humidity, $70 \pm 5 \%$; ambient temperature, $24 \pm 2{ }^{\circ} \mathrm{C}$ ) and were supplied with food and water ad libitum during the 1 week of acclimation before the start of the experiment. The rats were then randomly assigned to one of two groups. Group I $(n=3)$ was the drug group; these rats were given phloretin. Group II $(n=3)$, was the control group (i.e., no phloretin given). Before the experiment commenced, all rats were fasted for $12 \mathrm{~h}$ but had free access to water.
Phloretin was suspended in $0.5 \%$ carboxymethylcellulose sodium (CMC-Na) aqueous solution. Two hours after phloretin was given via the oral route (50 mg/kg body weight), the group 1 rats were anesthetized using ether and then euthanized using decapitation. Each group 2 rats was given $0.5 \% \mathrm{CMC}-\mathrm{Na}$ aqueous solution $2 \mathrm{~mL}$ via the oral route and was anesthetized and euthanized using the same procedures as the group 1 rats. A blood sample was withdrawn from each rat into heparinized centrifuge tubes and centrifuged (4000 rpm, 10 $\mathrm{min}$ ) to obtain the plasma, which was stored at $20^{\circ} \mathrm{C}$ until pretreatment and analyses.

The experiment was designed and performed in accordance with the guidelines established by Animal Experiments of Hunan University of Medicine. The study protocol was approved by the Animal Biomedical Ethical Committee of Hunan University of Medicine (approval no. kjdw-20171104-05) [15].

\section{Sample preparation}

A solid-phase extraction (SPE) method was used to pretreat each plasma sample. Each SPE cartridge was pretreated using successive rinses with water, methanol, and water (5 $\mathrm{mL}$ each). For each sample, $1 \mathrm{~mL}$ plasma was added to the SPE cartridge and flowed through by gravity. Water and then methanol ( $5 \mathrm{~mL}$ each) were then used to rinse the SPE cartridge. After collection, the methanol eluent was dried by evaporation at room temperature under $\mathrm{N}_{2}$ gas. Acetonitrile/water (100 $\mu \mathrm{L} ; 10: 90, v / v)$ was used to re-dissolve the residue and the sample was then centrifuged $\left(12,000 \mathrm{rpm}, 4^{\circ} \mathrm{C}, 30 \mathrm{~min}\right)$. A 2$\mu \mathrm{L}$ supernatant sample was analyzed by injection into the UHPLC-LTQ-Orbitrap MS.

\section{Instrumentation and conditions}

An ACQUITY BEH $\mathrm{C}_{18}$ column $(2.1 \times 100 \mathrm{~mm}$ i.d., $1.7 \mu \mathrm{m}$; Waters Corporation, Milford, MA, USA) and an Accela 600 UHPLC system equipped with a binary solvent delivery system and auto-sampler (Thermo Scientific, Bremen, Germany) were used for the chromatographic analysis and sample separation. The mobile phase chemicals were $0.1 \%$ formic acid aqueous solution (solvent A) and acetonitrile/methanol 3:1 (solvent B). The flow rate was $0.2 \mathrm{~mL} / \mathrm{min}$, applied with a linear gradient of $0-20 \mathrm{~min}, 10-$ $40 \% \mathrm{~B} ; 20-22 \mathrm{~min}, 40-70 \% \mathrm{~B} ; 22-25 \mathrm{~min}$, $70-80 \%$ B; $25-29 \min , 80 \%$ B;29 - 30min, $80-10 \% \mathrm{~B}$; and $30-35 \mathrm{~min}, 10 \% \mathrm{~B}$; at room temperature. 
The spectral analysis used high-resolution electrospray ionization (ESI)-MS and MS/MS performed on the LTQ-Orbitrap mass spectrometer connected to the UHPLC instrument via the ESI interface. The negative ion mode was used during sample analysis. The tune method settings consisted of a nitrogen sheath gas flow rate of 30 arb, a nitrogen auxiliary gas flow rate of 5 arb, a spray voltage of $4.0 \mathrm{kV}$, a capillary temperature of $350{ }^{\circ} \mathrm{C}$, a capillary voltage of $25 \mathrm{~V}$, and a tube lens voltage of $110 \mathrm{~V}$. Calibration was performed according to the manufacturer's guidelines to ensure an accurate mass analysis. The centroid mass spectra were acquired in the mass range of $\mathrm{m} / \mathrm{z}$ 100-1000.

The Orbitrap mass analyzer resolution was set at 30,000 during the full-scan experiment. The total analytical time was minimized during the datadependent MS/MS scanning to avoid generation of fragmentation spectra of the targeted ions. The collision-induced dissociation collision energy was adjusted to $35 \%$ of maximum, and the precursor ion isolation width was $m / z 2.0 \mathrm{Da}$. To prevent repetition, dynamic exclusion was enabled; the repeat count was set at 5 , the dynamic repeat time was set at $30 \mathrm{sec}$, and the dynamic exclusion duration was set at $60 \mathrm{sec}$.

\section{Peak selection and data processing}

Data acquisition and processing were performed using a Thermo Xcaliber 2.1 workstation. To maximize fragment ion detection, the peaks with intensities $>10,000$ were selected for identification. Chemical formulas were calculated for the parent ions of the selected peaks based on accurate mass values using a molecular formula predictor. The parameters were $\mathrm{C}$ [030], $\mathrm{H}$ [0-50], O [0-20], S [0-4], N [0-4], Cl [04]; the ring double bond equivalent value range was [0-15]. Because they were rarely present in the complex matrices obtained, other elements (e.g., $\mathrm{P}$ and $\mathrm{Br}$ ) were not included.

\section{RESULTS}

\section{Phloretin fragmentation pathway}

The phloretin $\mathrm{MS}^{n}$ fragmentation pattern was examined to assist with the characterization of metabolite structure. In negative ion mode, the parent ion had a deprotonated ion [M-H] at $\mathrm{m} / \mathrm{z}$ 273.07575 (2.8 ppm, $\mathrm{C}_{15} \mathrm{H}_{13} \mathrm{O}_{5}$; Figure 2). Loss of a moiety $\left(\mathrm{C}_{7} \mathrm{H}_{6} \mathrm{O}\right)$ during parent ion fragmentation revealed a fragment ion at $m / z 167$ $\left(2.5 \mathrm{ppm}, \mathrm{C}_{8} \mathrm{H}_{7} \mathrm{O}_{4}\right)$. These results indicated there was a fragment present at $m / z 125$; this fragment could have resulted from $\mathrm{C}_{2} \mathrm{H}_{2} \mathrm{O}$ loss from the ion at $m / z 167$.
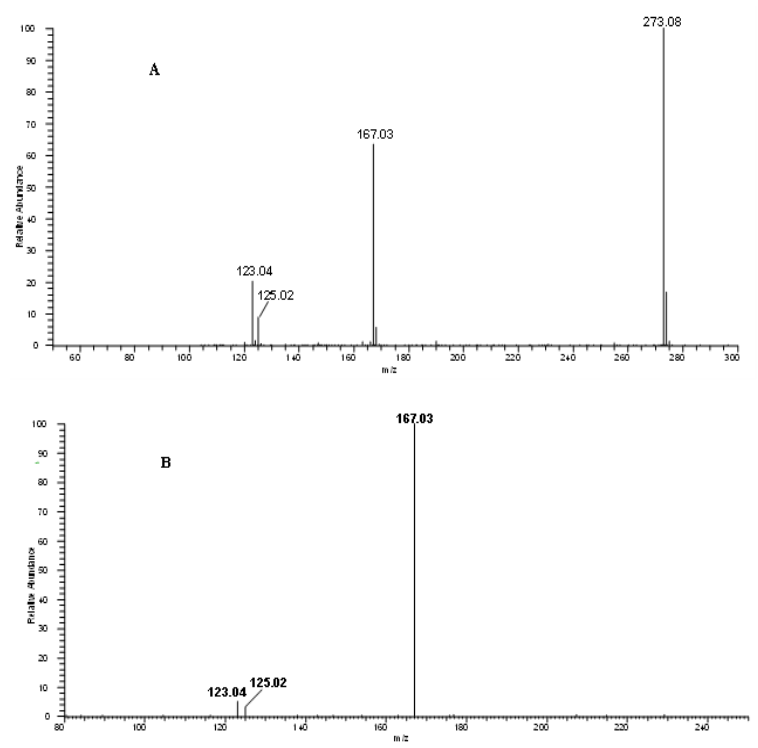

Figure 2: $\mathrm{MS}^{\mathrm{n}}$ spectra of phloretin

\section{Detection and determination of metabolite structure}

In addition to phloretin (the parent drug), 17 metabolites were found and underwent chromatographic and mass spectrometric analyses (Table 1) after comparing the highresolution extracted ion chromatography results for the samples from the rats who were given phloretin with the results for the plasma samples from the control rats (Figure 3 ).
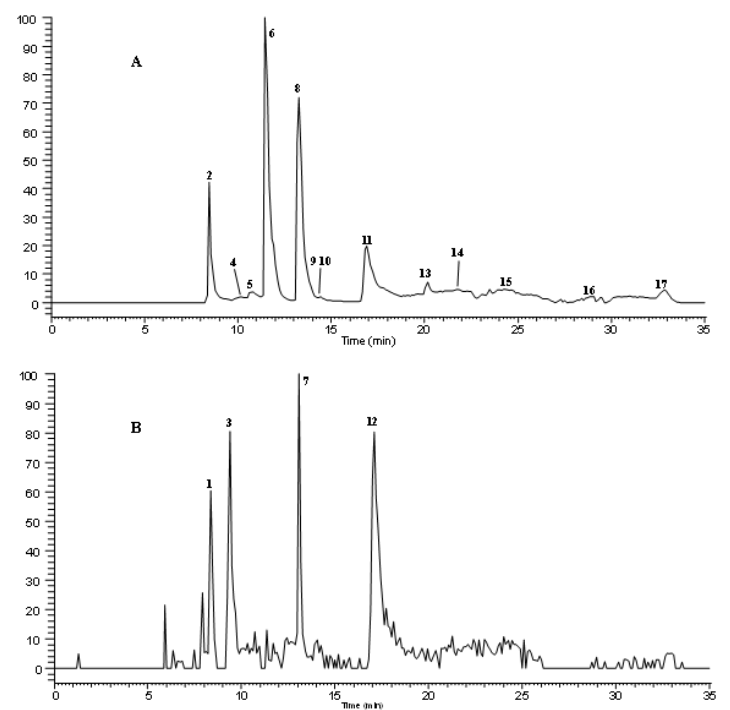

Figure 3: High-resolution extracted ion chromatography results in $5 \mathrm{ppm}$ for metabolites detected in rat plasma. A (m/z): 273.07553, 449.10783, 625.13983; B (m/z): 289.07062, 431.09726, 435.12860, 515.08502, 596.13916, 611.16046 
Table 1: Predicted elemental composition, experimental mass, and characteristic fragment ions for phloretin metabolites in rats

\begin{tabular}{|c|c|c|c|c|c|c|c|}
\hline $\begin{array}{l}\mathrm{Pe} \\
\text { ak }\end{array}$ & $t_{R}$ & $\begin{array}{c}\text { Theoretical } \\
\text { mass } m / z\end{array}$ & $\begin{array}{l}\text { Experimental } \\
\text { mass } m / z\end{array}$ & $\begin{array}{l}\text { Error } \\
(\mathrm{ppm})\end{array}$ & $\begin{array}{c}\text { Formula [M- } \\
\mathrm{H}^{-}\end{array}$ & MS/MS fragment & Identification/reactions \\
\hline 1 & 8.35 & 611.16046 & 611.16066 & -0.33 & $\mathrm{C}_{27} \mathrm{H}_{31} \mathrm{O}_{16}$ & $\begin{array}{c}\mathrm{MS}^{2}[611]: \text { 273.07523(48), 449.10458(26) } \\
\mathrm{MS}^{3} \text { [273]: 167(100) }\end{array}$ & $\begin{array}{l}\text { Glucosylation, Glucuronide } \\
\text { conjugation }\end{array}$ \\
\hline 2 & 8.47 & 625.13983 & 625.13992 & -0.15 & $\mathrm{C}_{27} \mathrm{H}_{29} \mathrm{O}_{17}$ & $\begin{array}{c}M^{2}[625]: \text { 449.10715(26), 273.07565(53) } \\
315.08612(3) \\
\operatorname{MS}^{3}[449]: 273(100)\end{array}$ & Diglucuronide conjugation \\
\hline 3 & 9.37 & 515.08502 & 515.08539 & -0.71 & $\mathrm{C}_{21} \mathrm{H}_{23} \mathrm{O}_{13} \mathrm{~S}$ & $\begin{array}{c}M^{2}[515]: \\
M^{2} S^{3}[273]: 167(100)\end{array}$ & $\begin{array}{l}\text { Glucosylation, Sulfate } \\
\text { conjugation }\end{array}$ \\
\hline 4 & $\begin{array}{c}10.4 \\
1\end{array}$ & 353.03244 & 353.03256 & -0.35 & $\mathrm{C}_{15} \mathrm{H}_{13} \mathrm{O}_{8} \mathrm{~S}$ & $\begin{array}{c}M^{2} \text { [353]: } 273.07523(100), 173.04492(6) \\
M^{3} \text { [273]: 167(100) }\end{array}$ & Sulfate conjugation \\
\hline 5 & $\begin{array}{c}10.8 \\
4\end{array}$ & 449.10783 & 449.10800 & 0.36 & $\mathrm{C}_{21} \mathrm{H}_{21} \mathrm{O}_{11}$ & $\begin{array}{c}\mathrm{MS}^{2}[449]: 273.07529(100) \\
167.03433(6), 315.08481(3) \\
\mathrm{MS}^{3}[273]: 167(100)\end{array}$ & Glucuronide conjugation \\
\hline 6 & $\begin{array}{c}11.4 \\
7\end{array}$ & 449.10783 & 449.10751 & -0.73 & $\mathrm{C}_{21} \mathrm{H}_{21} \mathrm{O}_{11}$ & $\begin{array}{c}\mathrm{MS}^{2}[449]: 273.07574(100) \\
167.03447(12), 315.08572(12) \\
\mathrm{MS}^{2}[273]: 163(100), 173(5)\end{array}$ & Glucuronide conjugation \\
\hline 7 & $\begin{array}{c}13.0 \\
7\end{array}$ & 435.12860 & 435.12857 & 0.06 & $\mathrm{C}_{21} \mathrm{H}_{23} \mathrm{O}_{10}$ & $\begin{array}{c}M^{2}[431]: 273.07520(100), 297.07523(14) \\
M^{3} \text { [273]: 167(100) }\end{array}$ & Glucosylation \\
\hline 8 & $\begin{array}{c}13.2 \\
8\end{array}$ & 449.10783 & 449.10822 & 0.85 & $\mathrm{C}_{21} \mathrm{H}_{21} \mathrm{O}_{11}$ & $\begin{array}{c}M^{2}[449]: \text { 273.07590(100), 167.03462(6) } \\
M^{3} \text { [273]: 167(100) }\end{array}$ & Glucuronide conjugation \\
\hline 9 & $\begin{array}{c}14.4 \\
3\end{array}$ & 449.10783 & 449.10757 & -0.60 & $\mathrm{C}_{21} \mathrm{H}_{21} \mathrm{O}_{11}$ & $\begin{array}{l}\mathrm{MS}^{2} \text { [449]: 273.07523(100) } \\
\mathrm{MS}^{3} \text { [273]: 167(100) }\end{array}$ & Glucuronide conjugation \\
\hline 10 & $\begin{array}{c}14.5 \\
3\end{array}$ & 353.03241 & 353.03256 & -0.44 & $\mathrm{C}_{15} \mathrm{H}_{13} \mathrm{O}_{8} \mathrm{~S}$ & $\begin{array}{l}\mathrm{MS}^{2}[353]: 273.07529(100) \\
\mathrm{MS}^{3}[273]: 167(100)\end{array}$ & Sulfate conjugation \\
\hline 11 & $\begin{array}{c}16.8 \\
9\end{array}$ & 353.03238 & 353.03256 & -0.52 & $\mathrm{C}_{15} \mathrm{H}_{13} \mathrm{O}_{8} \mathrm{~S}$ & $\begin{array}{l}\mathrm{MS}^{2} \text { [353]: 273.07550(100) } \\
\mathrm{MS}^{3} \text { [273]: } 167(100)\end{array}$ & Sulfate conjugation \\
\hline 12 & $\begin{array}{c}17.1 \\
0\end{array}$ & 289.07062 & 289.07066 & -0.15 & $\mathrm{C}_{15} \mathrm{H}_{13} \mathrm{O}_{6}$ & $\mathrm{MS}^{2}$ [289]: 183.02898(100),271.05746(11) & Hydroxylation \\
\hline 13 & $\begin{array}{c}20.1 \\
5\end{array}$ & 273.07553 & 273.07575 & -0.80 & $\mathrm{C}_{15} \mathrm{H}_{13} \mathrm{O}_{5}$ & $\mathrm{MS}^{2}$ [273]: 167(100) & Phloretin \\
\hline 14 & $\begin{array}{c}21.6 \\
6\end{array}$ & 353.03232 & 353.03256 & -0.69 & $\mathrm{C}_{15} \mathrm{H}_{13} \mathrm{O}_{8} \mathrm{~S}$ & $\begin{array}{c}\mathrm{MS}^{2} \text { [353]: 273.07535(100) } \\
\mathrm{MS}^{3}[273]: 167(100)\end{array}$ & Sulfate conjugation \\
\hline 15 & $\begin{array}{c}24.3 \\
3\end{array}$ & 353.03259 & 353.03256 & 0.07 & $\mathrm{C}_{15} \mathrm{H}_{13} \mathrm{O}_{8} \mathrm{~S}$ & $\begin{array}{l}\mathrm{MS}^{2} \text { [353]: 273.07525(100) } \\
\mathrm{MS}^{3} \text { [273]: 167(100) }\end{array}$ & Sulfate conjugation \\
\hline 16 & $\begin{array}{c}28.9 \\
5\end{array}$ & 353.19922 & 353.03256 & -0.04 & $\mathrm{C}_{15} \mathrm{H}_{13} \mathrm{O}_{8} \mathrm{~S}$ & $\begin{array}{l}\mathrm{MS}^{2} \text { [353]: 273.07520(100) } \\
\text { MS }^{3} \text { [273]: 167(100) }\end{array}$ & Sulfate conjugation \\
\hline 17 & $\begin{array}{c}32.8 \\
5\end{array}$ & 353.03262 & 353.03256 & 0.16 & $\mathrm{C}_{15} \mathrm{H}_{13} \mathrm{O}_{8} \mathrm{~S}$ & $\begin{array}{c}\mathrm{MS}^{2} \text { [353]: } 273.07529(100) \\
\mathrm{MS}^{3} \text { [273]: } 167(100)\end{array}$ & Sulfate conjugation \\
\hline
\end{tabular}




\section{Metabolite 13 (phloretin)}

Metabolite 13 eluted at 20.15 min with the quasimolecular $\mathrm{m} / \mathrm{z} 273.07553$ ions (-0.80 ppm, $\left.\mathrm{C}_{15} \mathrm{H}_{13} \mathrm{O}_{6}\right)$. The retention time, accurate $\mathrm{MS}$, and MS/MS spectra results were compared with reference values to identify metabolite 13 as phloretin.

\section{Metabolites 7, 1, and 3}

Metabolite 7 elution occurred at 13.07 min with the quasi-molecular $\mathrm{m} / \mathrm{z} 435.12857$ ions (0.06 ppm, $\mathrm{C}_{21} \mathrm{H}_{23} \mathrm{O}_{10}$ ). It was $162 \mathrm{Da}$ greater than phloretin, which suggested that metabolite 7 was a glucosylation product of the prototype drug. An ion present at $\mathrm{m} / \mathrm{z} 273.07520$ in the $\mathrm{MS}^{2}$ spectra was the result of a $162 \mathrm{Da}$ loss from the precursor ion at $m / z$ 435. This result also suggested that it was a glucosylation conjugation product of phloretin. Based on these results, metabolite 7 was categorized as a glucosylation conjugation product of phloretin.

Metabolite 1 included a deprotonated molecular ion $[\mathrm{M}-\mathrm{H}]^{-}$at $\mathrm{m} / \mathrm{z} 611.16046 \quad(-0.33 \mathrm{ppm}$, $\left.\mathrm{C}_{27} \mathrm{H}_{31} \mathrm{O}_{16}\right)$. It was $176.03 \mathrm{Da}$ greater than metabolite 7. This result suggested that metabolite 1 was a glucuronide conjugation product of metabolite 7 . Therefore, it was categorized as a glucuronide and glucosylation conjugation product of phloretin.

Metabolite 3 elution occurred at 9.37 min with the quasi-molecular $m / z 515.08502$ ions (-0.71 ppm, $\left.\mathrm{C}_{21} \mathrm{H}_{23} \mathrm{O}_{13} \mathrm{~S}\right)$. It was $79.96 \mathrm{Da}$ greater than metabolite 7. This result suggested that metabolite 3 was a sulfate conjugation product of metabolite 7 . This conclusion was supported by the presence of characteristic ions at $\mathrm{m} / \mathrm{z} 273$ and $m / z$ 167. Therefore, metabolite 3 was categorized as a sulfate and glucosylation conjugation product of phloretin.

\section{Metabolites 2, 5, 6, 8, and 9}

Metabolites 5, 6, 8, and 9 were eluted at 10.84, $11.47,13.28$, and $14.43 \mathrm{~min}$ with the quasimolecular $\mathrm{m} / \mathrm{z} 449.108$ ions $\left(\mathrm{C}_{21} \mathrm{H}_{21} \mathrm{O}_{11}\right)$. These metabolites were $176.03 \mathrm{Da}$ greater than phloretin. The same $\mathrm{m} / \mathrm{z} 273\left[\mathrm{M}-\mathrm{H}-\mathrm{C}_{6} \mathrm{H}_{8} \mathrm{O}_{6}\right]$ fragment ion was detected in the metabolites' $\mathrm{MS}^{2}$ spectra. These results suggested that they were phloretin metabolites, and they were identified as glucuronide conjugation products of phloretin.

Metabolite 2 included a deprotonated molecular ion $[\mathrm{M}-\mathrm{H}]^{-}$at $\mathrm{m} / \mathrm{z} 625.13983 \quad(-0.15 \mathrm{ppm}$, $\mathrm{C}_{27} \mathrm{H}_{29} \mathrm{O}_{17}$ ). It was $176.03 \mathrm{Da}$ and $352.06 \mathrm{Da}$ greater than metabolite 5 and phloretin, respectively. Based on these results, metabolite 2 was characterized as a diglucuronide conjugation product of phloretin.

\section{Metabolites 4, 11, 10, 14, 15, 16, and 17}

Metabolites 4, 10, 11, 14, 15, 16, and 17 were eluted at $10.41,14.53,16.89,21.66,24.33$, 28.95 , and $32.85 \mathrm{~min}$, respectively. Their accurate mass shift value was $79.96\left(\mathrm{SO}_{3}\right) \mathrm{Da}$ greater, compared with phloretin. These results suggested that metabolites $4,10,11,14,15,16$, and 17 were mono-sulfate conjugation products and that they were sulfate conjugation products of phloretin.

\section{Metabolite 12}

Metabolite 12 elution was at 17.10 min with the quasi-molecular $\mathrm{m} / \mathrm{z} 289.07062$ ions $(-0.15 \mathrm{ppm}$, $\mathrm{C}_{15} \mathrm{H}_{13} \mathrm{O}_{6}$ ). It was $16 \mathrm{Da}$ greater than phloretin. Therefore, metabolite 12 was identified as a mono-hydroxylated product of the prototype drug.

\section{Possible metabolic pathways of phloretin}

The analysis revealed the parent drug (metabolite 13) and a total of 16 other metabolites in the plasma samples. Taken together, the results suggested that phloretin in vivo underwent various metabolic reactions such as hydroxylation (metabolite 12), glucosylation (metabolite 7), sulfate conjugation (metabolites 4 , $10,11,14,15,16$, and 17), glucuronide conjugation (metabolites 5, 6, 8, and 9), glucosylation and glucuronide conjugation (metabolite 1), diglucuronide conjugation (metabolite 2), and glucosylation and sulfate conjugation (metabolite 3 ).

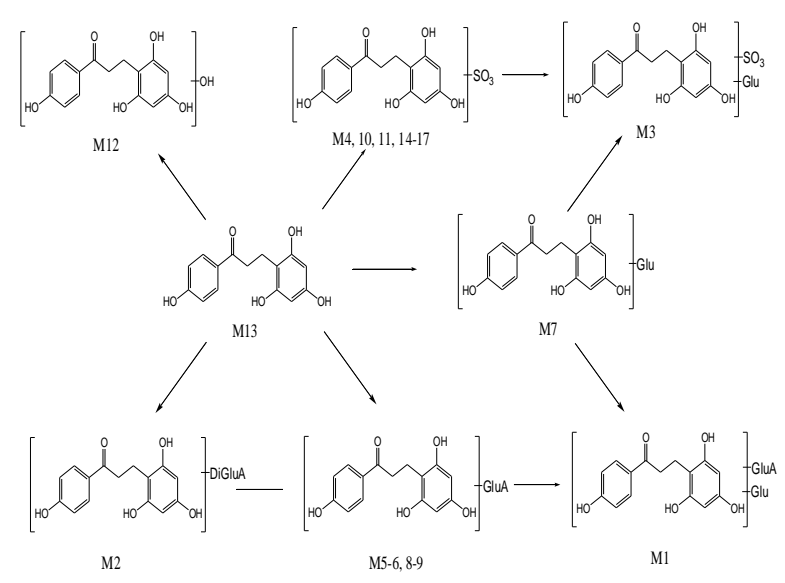

Figure 4: Possible metabolic pathways of phloretin in the plasma 


\section{DISCUSSION}

A UHPLC-LTQ-Orbitrap mass spectrometry method was used to analyze the metabolites of phloretin in vivo. To improve the separation results, mobile phase (e.g., methanol-water, acetonitrile-water, and acetonitrile-methanolwater) system optimization was performed. The results indicated that a mobile phase consisting of an acetonitrile-methanol $(3: 1 / \mathrm{v}: \mathrm{v})$ and formic acid $(0.1 \%)$ aqueous solution improved the chromatographic peak resolution of the phloretin, its metabolites, and the endogenous components.

In this study, phloretin (a dihydrochalcone) was detected using ESI in negative ion mode [16]. ESI provided greater response intensities and reduced spectral interference. Some work on the identification of metabolites of phloretin has been performed [17-18]. For example, one study did find sulfate and phloretin conjugates in rat plasma [18]. However, more studies to identify phloretin metabolites should be performed.

\section{CONCLUSION}

Metabolites can possess pharmacological and toxic activities. Therefore, the early stages of drug investigations include drug metabolite characterization. In this study, phloretin and its metabolites were found and categorized in plasma from rats given phloretin per os. These results contribute to our understanding of phloretin's effective forms, metabolic fates, and pharmacological and toxic actions in vivo.

\section{DECLARATIONS}

\section{Acknowledgement}

This work was supported by the National Natural Science Foundation of China (no. 81603393), the Natural Science Foundation of Hunan Province (no. 2018JJ3376), the Hunan Provincial Key Laboratory of Dong Medicine (no. 2015TP102003), and the Platform Construction Project of the Hunan Provincial Key Laboratory of Dong Medicine (no. 2017CT5025).

\section{Conflict of interest}

No conflict of interest is associated with this work.

\section{Contribution of authors}

We declare that this work was done by the authors named in this article and all liabilities pertaining to claims relating to the content of this article will be borne by the authors. WC and LL conceived and designed the study, FW and LL. collected the data, WC, P.J., H.P., and Z.Y. analyzed the data, and FW, LL, and WC wrote the manuscript. All authors read the manuscript and approved submission for publication.

\section{Open Access}

This is an Open Access article that uses a funding model which does not charge readers or their institutions for access and distributed under the terms of the Creative Commons Attribution License (http://creativecommons.org/licenses/by/ 4.0) and the Budapest Open Access Initiative (http://www.budapestopenaccessinitiative.org/rea d), which permit unrestricted use, distribution, and reproduction in any medium, provided the original work is properly credited.

\section{REFERENCES}

1. Yang YC, Lii CK, Lin AH, Yeh YW, Yao HT, Li CC, Liu $K L$, Chen HW. Induction of glutathione synthesis and heme oxygenase 1 by the flavonoids butein and phloretin is mediated through the ERK/Nrf2 pathway and protects against oxidative stress. Free Radic Biol Med 2011; 51(11): 2073-2081.

2. Kim MS, Kwon JY, Kang NJ, Lee KW, Lee HJ. Phloretin induces apoptosis in H-Ras MCF 10A human breast tumor cells through the activation of p53 via JNK and p38 mitogen-activated protein kinase signaling. Ann NY Acad Sci 2009; 133(1171): 479-483.

3. Wu CH, Ho YS, Tsai CY, Wang YJ, Tseng H, Wei PL, Lee $C H$, Liu RS, Lin SY. In vitro and in vivo study of phloretin-induced apoptosis in human liver cancer cells involving inhibition of type II glucose transporter. Int $J$ Cancer 2009; 124 (9): 2210-2219.

4. Yang KC, Tsai CY, Wang YJ, Wei PL, Lee CH, Chen JH, $W u \mathrm{CH}$, Ho YS. Apple polyphenol phloretin potentiates the anticancer actions of paclitaxel through induction of apoptosis in human hep G2 cells. Mol Carcinog 2009; 48(5): 420-431.

5. Choi BM, Chen $X Y$, Gao SS, Zhu R, Kim BR. Antiapoptotic effect of phloretin on cisplatin-induced apoptosis in HEl-OC1 auditory cells. Pharmacol Rep 2011; 63 (3): 708-716.

6. Lu XY, Zeng YY, Ye YX, Zhou YY, Mu JJ, Zhao XH. Antiinflammatory and immunosuppressive effect of phloretin. Acta Pharmaceutica Sinica 2009; 44(5): 480-485.

7. Hassan M, El Yazidi C, Malezet-Desmoulins C, Amiot MJ, Margotat A. Gene expression profiling of 3T3-L1 adipocytes exposed to phloretin. J Nutr Biochem 2010; 21(7): 645-652.

8. Olson ML, Kargacin ME, Ward CA, Kargacin GJ. Effects of phloretin and phloridzin on Ca2+ handling, the action

Trop J Pharm Res, October 2019; 18(10):2172 
potential, and ion currents in rat ventricular myocytes. $J$ Pharmacol Exp Ther 2007; 321 (2): 921 -329.

9. Olson ML, Kargacin ME, Honeyman TW, Ward CA, Kargacin GJ. Effects of phytoestrogens on sarcoplasmic/endoplasmic reticulum calcium ATPase $2 a$ and $\mathrm{Ca} 2+$ uptake into cardiac arcoplasmic reticulum. $J$ Pharmacol Exp Ther 2006; 316(2): 628-635.

10. Stangl V, Lorenz M, Ludwig A, Grimbo N, Guether C, Sanad W, Ziemer S, Martus P, Baumann G, StangI K.The flavonoid phloretin suppresses stimulated expression of endothelial adhesion molecules and reduces activation of human platelets. J Nutr 2005; 135(2): 172-178.

11. Wani TA, Zargar S. New Highly-Sensitive UltraPerformance Liquid Chromatography-Mass Spectrometry Method for Quantification of Telmisartan in Human Plasma. Trop J Pharm Res 2015; 14 (3): 511 518.

12. Zhang J, Wang F, Cai W, Zhang Q, Liu Y, Li Y, Liu R, Cao $G$. Identification of metabolites of gardenin $A$ in rats by combination of high-performance liquid chromatography with linear ion trap Orbitrap mass spectrometer based on multiple data processing techniques. Biomed Chromatogr. 2015; 29(3): 379-387.
13. Zhang J, Cai W, Zhou Y, LiU Y, Wu XD, Li Y, Lu JQ, Qiao $Y J$. Profiling and identification of the metabolites of baicalin and study on their tissue distribution in rats by ultra-high-performance liquid chromatography with linear ion trap-Orbitrap mass spectrometer. J Chromatogr B 2013; 985: 91-102

14. Wu FP, Yang Y, Liu LH, Pu H, Jin P, Yao ZH, Cai W. Profiling and identification of the metabolites of evodiamine in rats using ultra-performance liquid chromatography with linear ion trap orbitrap mass spectrometer. Trop J Pharm Res 2016; 15(3): 623-629

15. Olfert ED, Cross BM, McWilliam AA. Guide to the care and use of experimental animals. Vol. 1. No. 2. Ottawa: Canadian Council on Animal Care, 1993.

16. Shao X, Bai N, He K, Ho CT, Yang CS, Sang S. Apple polyphenols, phloretin and phloridzin: new trapping agents of reactive dicarbonyl species. Chem Res Toxicol 2008; 21(10), 2042-2050.

17. Crespy V, Aprikian O, Morand C, Besson C, Manach C, Demigné C, Rémésy C. Bioavailability of phloretin and phloridzin in rats. J Nutr 2001; 131(12), 3227-3230.

18. Monge P, Solheim E, Scheline RR. Dihydrochalcone metabolism in the rat: phloretin. Xenobiotica 1984; 14(12): 917-924. 